\title{
Viabilidade econômica e financeira de uma fábrica de argamassas em Mafra/SC
}

\author{
Economic and financial of a cement factory in Mafra/SC
}

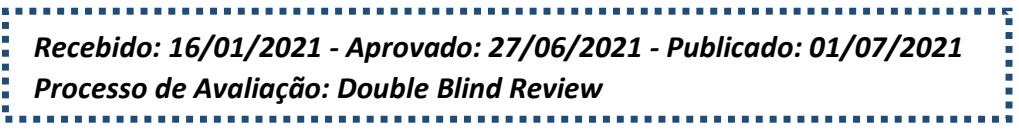

\author{
Vinícius Sabatke ${ }^{1}$ \\ Rodolfo Vieira Nunes ${ }^{2}$ \\ George André Willrich Sales ${ }^{3}$
}

\section{RESUMO}

O mercado brasileiro de argamassas industrializadas está estimado em 120 milhões de toneladas, sendo no que o sul brasileiro concentra $15 \%$ da demanda nacional de produção de Argamassas. Grandes players fazem parte desse mercado, criando um grande desafio para os empreendedores que têm interesse em concorrer nesse segmento de mercado da construção civil. Entretanto com uma demanda avolumada como essa faz com que questiona-se qual a viabilidade econômica de uma indústria de argamassas em Mafra/SC?. Como metodologia para o desenvolvimento do estudo foi realizada pesquisa de levantamento por meio de dados primários e secundários, com questionários semiestruturados para fornecedores, e obtenção de informações mercadológicas e técnicas na internet, respectivamente. Foram considerados todos os insumos e infraestrutura para a elaboração dos resultados alcançados. Para a viabilidade deste empreendimento, foram avaliados, investimentos iniciais, Valor Presente Líquido (VPL), Taxa Interna de Retorno (TIR), Taxa Mínima de Atratividade (TMA), Índice de Lucratividade (IL) e Payback descontado. A Empresa mostrou-se economicamente viável tendo em um cenário realista o VPL positivo em R\$ 3.507.589,14, TIR de 81,34\%, Payback Descontado de 1,6 anos e IL de 4,89.

Palavras-chave: construção civil; rentabilidade; atratividade; plano de negócios.

\begin{abstract}
The Brazilian market for industrialized cement is estimated at 120 million tons, with the southern Brazilian region concentrating $15 \%$ of the national demand for mortar production. Large players are part of this market, creating a great challenge for entrepreneurs who are interested in competing in this segment of the civil construction market. However, with such a huge demand, it is questioned what is the economic viability of a cement industry in Mafra/SC? As a methodology for the development of the study, a survey was conducted using primary and secondary data, with semi-structured questionnaires for suppliers, and obtaining market and technical information on the internet, respectively. All inputs and infrastructure were considered for the preparation of the results achieved. For the feasibility of this project, initial investments, Net Present Value (NPV), Internal Rate of Return (IRR), Minimum Rate of Attractiveness (MRA), Profitability Index (PI) and Discounted Payback were evaluated. The Company proved to be economically viable, in a realistic scenario, with a positive NPV of R $\$ 3,507,589.14$, IRR of $81.34 \%$, Discounted Payback of 1.6 years and PI of 4.89.
\end{abstract}

\footnotetext{
${ }^{1}$ Graduado em Sistema de Informação pela Universidade do Contestado - UnC. Pós-Graduado (MBA) em Gestão de Projeto pela Universidade de São Paulo - ESALQ/USP. Brasil. Email: viniciusdesapp@ gmail.com.

${ }^{2}$ Doutorando em Administração pela Universidade de São Paulo - FEA/USP. Professor Substituto na Universidade Estadual do Maranhão - UEMA e Professor Designado na Universidade do Estado de Minas Gerais. Brasil. Email: rodolfovieiran@yahoo.com.br.

${ }^{3}$ Doutor em Administração de Empresas pela Universidade Presbiteriana Mackenzie. É professor do Mestrado pela Faculdade FIPECAFI e professor na Universidade Federal de São Paulo - UNIFESP. Brasil. Email: george.sales@ fipecafi.org
} 
Keywords: construction; profitability; attractiveness; business plan.

\section{INTRODUÇÃO}

O mercado da construção civil segundo o Serviço de Apoio às Micro e Pequenas empresas de Santa Catarina (Sebrae-SC, 2020) apontou que um dos principais braços da econômica brasileira é a construção civil, onde é responsável por 6,2\% do Produto Interno Bruto brasileiro com um faturamento acima de 1 trilhão de reais, impactando mais de 70 setores da economia brasileira, também apontou o Sebrae-SC (2020), que o setor emprega cerca de 12,5 milhões de pessoas e apenas Santa Catarina possui formalizado mais de 17.500 estabelecimentos comerciais atuantes no setor.

Após um período de cinco anos apresentando resultados negativos o mercado da construção civil voltou a prosperar em 2019 mostrando um crescimento de 1,7\% comparado com o mesmo período no ano de 2018 segundo Instituto Brasileiro de Geografia e Estatística (IBGE, 2020). A projeção para o ano de 2020 segundo Associação Brasileira da Construção Industrializada de Concreto - ABCIC (2020) nos mostra que foi projetado uma queda de faturamento maior que $10 \%$, indicando um momento complicado para o setor e os principais segmentos da economia brasileira, que nos últimos anos vem sofrendo com a recessão.

A Análise de viabilidade econômica e financeira foi realizado sobre um projeto industrial, onde este terá as suas instalações no estado de Santa Catarina, um dos estados que demonstrou forte crescimento no setor da Construção Civil partindo de uma retração $-5 \%$ do Produto Interno Bruto da Construção Civil no ano de 2017 para um crescimento anual médio de 1,7\% nos anos seguintes segundo Sebrae-SC (2019). As informações referente a análise macroeconômica foram levantadas junto a Federação da Indústrias do Estado de Santa Catarina (FIESC, 2020) apontando em uma de suas análises que o empresário catarinense projeta para 2020 a retomada no crescimento da economia em geral, tendo como indicador o nível de confiança que chegou na casa de 66,9 pontos, enquanto a média nacional reflete 56,6 pontos, aponta também outro indicador o índice de Atividade Econômica que acumulou até o final de 2019 uma alta de 2,8\% contra a média nacional que ficou em $0,95 \%$ e podendo ter um crescimento da atividade industrial de $2,6 \%$ contra $-1,1 \%$ da média industrial do país comparando os períodos anteriores. Esse cenário demonstra ser mais positivo para novos investimentos em relação aos últimos anos. 
Segundo a Associação Brasileira de Argamassas Industrializadas - ABAI (2015), o Brasil possui um mercado de argamassas industrializadas e não industrializadas estimado em 120 milhões de toneladas anuais, sendo que apenas o sul brasileiro representa $15 \%$ dessa demanda totalizando 18 milhões de toneladas por ano.

A indústria da argamassa, acompanha as oscilações do mercado da construção civil, devido ao baixo valor agregado e a concorrência acirrada, ser líder em custo não é uma opção e sim pré-requisito para o empreendedor que possa atuar nessa área. A busca por vantagem competitiva, faz com que as empresas do ramo busquem alternativas para tornarem-se economicamente viáveis, buscando por insumos mais baratos, logísticas mais eficientes ou agregando valor a outras regras de negócios já pré-estabelecidas.

O mercado de Argamassas é extremamente competitivo, portanto buscou-se durante a estruturação do projeto, utilizar um bom posicionamento logístico a fim de se fazer competitivo perante a concorrência. O projeto foi implementado estrategicamente em paralelo com um dos fornecedores mais importantes, o fornecedor de areia fina produto que tem o menor valor agregado em relação aos demais insumos utilizados sendo mais sensível ao custo de transporte assim encarecimento do produto.

Objetivo deste trabalho é analisar a viabilidade econômico-financeira de um empreendimento industrial de argamassas tipo AC1 a ser instalada no Sul do Brasil na cidade de Mafra/SC. O levantamento de informações considerou o cenário brasileiro, cadeia produtiva da construção civil, infraestrutura necessária, investimentos e retorno financeiro.

\section{REFERENCIAL TEÓRICO}

\subsection{Mercado}

Conhecer o mercado no qual a empresa atuará é fundamental para realizar a estruturação do projeto bem como as suas premissas como, preço, qualidade do produto, concorrentes entre outros fatores importantes que poderão interferir diretamente no resultado financeiro da empresa. No entendimento de Dornelas (2016) conhecer os concorrentes, preços de venda e demanda são fundamentais para o sucesso de um empreendimento bem como analisar a rentabilidade ideal que viabiliza o investimento. Para Dornelas (2016), os empreendedores deverão responder questões mercadológicas fundamentais para que o seu negócio possa ter sucesso, a ausência dessas informações, poderá conduzir o empresário a um caminho no qual se 
encontrará sem informações relevantes para a tomada de decisão, e facilmente será surpreendido por questões para as quais uma boa pesquisa de mercado poderia ter evitado.

\subsection{Análise de investimentos}

A análise de investimento é realizada quando surge a necessidade de entender se um determinado projeto é viável ou não. Para este estudo, foram realizados procedimentos relacionados à viabilidade econômica e financeira de um novo empreendimento, tendo em mente, estruturar uma análise da rentabilidade que a iniciativa trará a seus investidores.

Aplicando procedimentos técnicos relacionados a análise econômica e financeira, o empreendedor terá clareza sobre o investimento e qual a possível remuneração do seu capital, apontando o retorno do investimento e o prazo que acontecerá (BRUNI \& FAMÁ, 2008).

Para Assaf Neto (2014), uma empresa só cria valor acionistas, quando ela ultrapassa o custo de oportunidade esperado por eles, ou seja, quando supera a expectativa de rentabilidade exigida pelos investidores.

Os investimentos necessários para a estruturação de uma indústria de argamassa são elevados, pois necessitam de processos homogeneização de elementos e armazenamento de produtos em estado natural, além de ter estruturas que comportem a estocagem do material pronto. Segundo Sebrae (2011) num estudo onde aponta o investimento ideal para a construção de uma indústria de argamassas, descreve que boa parte dos equipamentos podem ser adquiridos em estado usado, pois a manutenção preventiva basta para o bom funcionamento da indústria e reduzirá significativamente o investimento inicial na planta.

\subsection{Indicadores Econômicos e Financeiros}

Indicadores são técnicas utilizadas para a análise econômica e financeira de empresas, nessa análise foram utilizados os seguintes procedimentos, Taxa Interna de Retorno (TIR), Payback Descontado, Índice de Lucratividade (IL) e Valor Presente líquido (VPL). 
- Índice de Lucratividade

Segundo Assaf Neto (2020), Índice de Lucratividade (IL) é um índice que avalia quando um projeto retorna em relação ao valor investido. Em outras palavras, se eu invisto um valor, espero receber o valor investido mais um percentual sobre ele. Encontramos esse valor quando trazemos a valor presente os fluxos de caixa e dividimos pelo investimento realizado, seguinte a seguinte form. (1):

$$
\mathrm{IL}=\frac{\text { Valor presente dos fluxos de caixas projetados }}{\text { Valor do Investimento }}
$$

\section{- Taxa Mínima de Atratividade}

Indicadores financeiros norteiam a tomada de decisão sobre investimentos, alguns como a Taxa Mínima de Atratividade (TMA), fazem com que tenhamos um comparativo sobre o que se esperar de um projeto em termos de remuneração do capital do investidor. Segundo Assaf Neto (2020), a Taxa Mínima de Atratividade é a taxa de juros que representa o mínimo que um investidor espera receber após aplicar os seus recursos em um empreendimento ou o máximo que ele aceita pagar por tomar capital emprestado. Esse parâmetro, alinhado com outros indicadores, faz com que a tomada de decisão sobre investir ou não nesse projeto, se torna mais palpável. No entendimento de Zdanowicz (2002), a TMA é difícil de se definir pois em sua composição deverá ser levado em consideração inúmeras variáveis subjetivas de caráter mercadológicos, políticos, concorrenciais, cambiais, monetária e tributária, riscos internacionais e até mesmo riscos de soberania do país onde os investimentos estão sendo realizados. Para Zdanowicz (2002), devemos tomar muito cuidado na definição da TMA pois se valorarmos de forma incorreta, o investimento em questão poderá se tornar inviável apresentando um Valor Presente Líquido (VPL) negativo, assim, tornando-o, inviável no olhar econômico e financeiro. Para este trabalho, foi definido uma taxa mínima de atratividade definida com base na taxa de juros imposta pelo Banco Nacional do Desenvolvimento (BNDES, 2020), onde ele define uma taxa máxima para financiamento de atividades industriais de pequeno e médio porte, chegando ao máximo de 14,13\% a.a. Segundo o Banco Central do Brasil (BACEN, 2020) a média de taxa de juros para financiamento de empresas nos bancos privados está em 17,63\% a.a. 
- Taxa Interna de Retorno

Um dos indicadores mais utilizados para analisar a rentabilidade de um empreendimento é a Taxa Interna de Retorno (TIR). Ela é em percentual o retorno sobre o investimento. Na visão de Zdanowicz (2002), a TIR tenta trazer todos as análises de investimento em um único indicador, utilizada como referência para a aceite de um investimento, se a TIR for positiva devemos aceitar o investimento. A TIR é a taxa de desconto que faz com que o VPL iguale a 0. Deve seguir a seguinte form. (2):

$$
V P L=\sum_{j=0}^{n} \frac{F C j}{(1+i)}-I_{0}
$$

Sendo que, $\mathrm{FC}_{\mathrm{j}}$ é o valor presente das entradas de caixa; $I_{0}$ é o investimento inicial, $i$ é a taxa de desconto; t é o tempo de desconto em cada entrada de caixa; n é o tempo de desconto do último fluxo de caixa.

\section{- Valor Presente Líquido}

Uma das ferramentas utilizada e que mais se adequa quando se tem a necessidade de avaliar um investimento. Sua formulação é bastante interessante, pois na sua composição levase em consideração fatores como valor do dinheiro no tempo. Isso permite a atualização do capital, que reflete diretamente nas receitas e custos referente aos períodos analisados e que contemplam o período de operação da empresa. Segundo Rêgo, Paulo, Spritzer e Zotoes (2013), o cálculo do Valor Presente Líquido (VPL) deve seguir a seguinte form. (3):

$$
V P L=\left[\sum_{T=1}^{n} \frac{F C_{\tau}}{(1+k)^{t}}\right]-\left[I_{0}+\sum_{t=1}^{n} \frac{l_{\tau}}{(1+k)^{-t}}\right]
$$

onde, $\mathrm{FC}_{\mathrm{t}}$ : é o fluxo de caixa no período t, com t variando de 1 a n, com n igual a 10 anos; K: é taxa de desconto do projeto, representada pela Taxa Mínima de Atratividade - TMA; 0 I : é o investimento inicial no momento zero; e t I : é valor do investimento previsto em cada período.

\section{- Payback Descontado}

Representa quanto tempo o investidor levará para recuperar o capital investido no empreendimento, segundo Rêgo et al. (2013), o investidor ponderara o prazo máximo para recuperar o capital que foi investido no projeto a uma taxa de desconto preestabelecida. Se o empreendimento atingir o resultado definido como premissa em relação ao tempo de retorno, o 
projeto encontra-se dentro da perspectiva do investidor. A diferença entre o Payback Simples e Payback Descontado é que no Payback simples não se usa uma taxa de desconto para realização de seu cálculo ao contrário do Payback descontato.

\section{METODOLOGIA}

Do ponto de vista da sua natureza este estudo se classifica como pesquisa aplicada, já que objetiva gerar conhecimentos para aplicação prática dirigidos à solução de problemas específicos, envolvendo verdades e interesses locais (Gil, 2010).

Quanto ao ponto de vista da forma de abordagem do problema esta pesquisa se classifica como qualitativa, já que considera que há uma relação dinâmica entre o mundo real e o sujeito, isto é, um vínculo indissociável entre o mundo objetivo e a subjetividade do sujeito que não pode ser traduzido em números. Segundo Gil (2002), a interpretação dos fenômenos e a atribuição de significados são básicas no processo de pesquisa qualitativa, não requerendo o uso de métodos e técnicas estatísticas. O ambiente natural é a fonte direta para coleta de dados e o pesquisador é o instrumento-chave (Gil, 2002)

Com relação aos seus objetivos, este estudo se classifica como pesquisa exploratória, pois visa proporcionar maior familiaridade com o problema com vistas a torná-lo explícito (Malhorta, 2001). Segundo o autor, envolve levantamento bibliográfico; entrevistas com pessoas que tiveram experiências práticas com o problema pesquisado; análise de exemplos que estimulem a compreensão.

Do ponto de vista dos procedimentos técnicos utilizados neste estudo, foram utilizados: pesquisa bibliográfica, pesquisa documental e pesquisa de levantamento. A pesquisa bibliográfica foi desenvolvida a partir de material já publicado, constituído principalmente de livros, artigos de periódicos e com material disponibilizado na Internet com a finalidade de agrupar informações conceituais para o suporte do estudo, bem como conhecer com maior profundidade o segmento de negócio no qual o empreendimento analisado se encontra. Quanto a pesquisa documental, foi elaborada a partir de materiais que não receberam tratamento analítico, como tendências do setor de construção civil e do segmento de negócio analisado, possibilitando base para as simulações realizadas. A pesquisa de levantamento foi utilizada para a interrogação direta das pessoas cujo comportamento se deseja conhecer por meio de entrevista semiestruturada com sujeitos vinculados ao segmento de negócio com questões relacionadas, 
principalmente, com a operação do empreendimento, insumos, capacidade fabril, entre outras informações.

A pesquisa foi realizada entre os dias 02 abril 2020 e 30 abril 2020. A amostra qualificase como não probabilística por adesão, também conhecida como amostra por voluntários embasada em critérios de conveniência, especialmente a acessibilidade e disponibilidade dos respondentes, sendo entrevistados 8 empresários do segmento de negócio, nas cidades de Mafra (SC) e Canoinhas (SC). Quanto ao horizonte de tempo a pesquisa é classificada como transversal, já que se restringe a um único período de avaliação (Richardson, 1999).

A análise de conteúdo foi aplicada para conversão dos dados primários coletados na entrevista e secundários obtidos nas pesquisas bibliográficas e documental, em informações relevantes para a análise de viabilidade do empreendimento. A principal função da análise de conteúdo é estabelecer inferência sobre um determinado conteúdo. De acordo com Bardin (2011), essa análise é um procedimento intermediário entre a descrição, que compreende a identificação das principais características do conteúdo analisado, e a interpretação, que compreende o significado das características extraídas do texto.

\section{RESULTADOS}

A estruturação da análise é um estudo sobre viabilidade econômica e financeira sobre o projeto que simulará a construção de uma indústria de argamassa, sendo que a mesma será situada no Município de Mafra-SC localizada no Planalto Norte Catarinense, próximo à divisa com o Município de Rio Negro-PR, é localizada a cerca de 300 km da capital de Santa Catarina, Florianópolis a 116 km da Capital do Paraná, Curitiba, Mafra é uma cidade com uma logística e infraestrutura rodoviária importantes está no entroncamento que direciona ao sul do Brasil, Litoral Catarinense e Eixo de Curitiba a São Paulo. A indústria será alocada em um ambiente anexo a uma extração de areia fina, um dos principais insumos para a fabricação do modelo de argamassa que será fabricado por esta planta.

\section{- Demanda do mercado de Argamassas Industrializadas e preços}

Tendo em vista a que as informações relativas ao mercado de Argamassas Industrializadas são escassas, buscou-se informações com representantes do setor no Brasil. A Associação de Argamassas Industrializadas (ABAI, 2015) relata que a produção nacional total de argamassas industrializadas e não industrializadas de chega a 120 milhões de toneladas ano, 


\section{能 CAFI}

SABATKE, Vinícius; NUNES, Rodolfo Vieira; SALES, George André Willrich. (2021) Viabilidade econômica e financeira de uma fábrica de argamassas em Mafra/SC. Cafi, v. 4 n. 2, p. 168 - 190. ISSN 2595-1750

apenas o sul brasileiro, região onde a indústria estará atuando representa 18 milhões de toneladas produzidas anualmente, chegando à $15 \%$ da produção total do país. Participam deste mercado grandes concorrentes, que acabam elevando o nível de competitividade do segmento. A distribuição da demanda está presentada no gráfico abaixo conforme a Figura 1.

Figura 1 - Mercado Brasileiro de Argamassa 2015

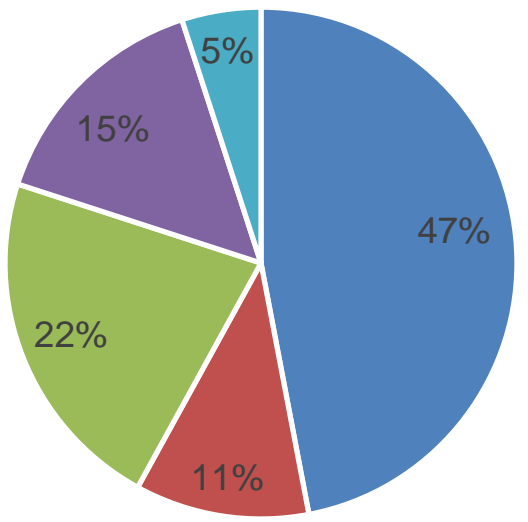

- Suldeste - Centro-oeste $\quad$ Nordeste - Sul - Norte

Fonte: Elaborado pelos autores (2020).

Buscou-se Informações sobre os preços de venda de Argamassa do tipo AC1 praticados na região do Planalto Norte Catarinense. Foram analisadas as principais marcas atuantes nesta região. Com base nas informações coletadas em e-commerce, definimos o preço de comercialização do produto. Para análise comercial, precificou-se o produto fabricado pela indústria da seguinte forma: Cenário pessimista definiu-se que o preço de venda seria $80 \%$ do menor do que o preço de venda encontrado no mercado regional, sendo precificado em $\mathrm{R} \$ 5,13$ a unidade de Argamassa AC1 20kg. No Cenário Realistas, levando em consideração que é uma empresa nova no mercado, com marca desconhecida e produto com qualidade similar a concorrência, o preço de venda foi fixado igual ao menor preço identificado no mercado regional sendo R \$ 6,41 a unidade de Argamassa AC1 20kg. No Cenário Otimista, elevamos o preço da unidade de Argamassa AC1 20kg ao valor médio de venda praticado na região, sendo de R\$ 8,08 a unidade de Argamassa AC1 20kg; 


\section{能CAFI}

SABATKE, Vinícius; NUNES, Rodolfo Vieira; SALES, George André Willrich. (2021) Viabilidade econômica e financeira de uma fábrica de argamassas em Mafra/SC. Cafi, v. 4 n. 2, p. 168 - 190. ISSN 2595-1750

Tabela 1: Concorrentes regionais no Planalto Norte Catarinense

\begin{tabular}{l|r}
\hline Concorrente & Preço da Argamassa AC1 20 kg \\
\hline Quartzolite & ------ \\
\hline Weber & 9,90 \\
\hline Fortaleza & 9,69 \\
\hline Votomassa & 8,99 \\
\hline Argatex & 8,89 \\
\hline Royal & 7,99 \\
\hline Colafix & 7,90 \\
\hline Arglass & 7,12 \\
\hline Porto Kroll & 6,99 \\
\hline Argamax & 6,91 \\
\hline
\end{tabular}

Fonte: Elaborado pelos autores (2020).

\section{- Projeção da demanda e produção}

Segundo o Sebrae (2011), sobre o mercado da construção civil, descreve que à argamassa do tipo AC1 representa $80 \%$ do total das argamassas produzidas no Brasil, totalizando apenas no sul brasileiro uma quantidade de 14.400.000 de toneladas ano. Aparentando-se ser um mercado com uma demanda bastante avolumada. Com base nessa informação, a planta que fará o beneficiamento e industrialização do produto foi projetada para que possa atender uma necessidade de produção em alta escala, suportando a produção da argamassa do tipo AC1. A produção anual inicial será de 7.200 toneladas e 360.000 unidades de argamassa de $20 \mathrm{~kg}$, chegando ao final dos 10 anos 8.604,67 toneladas e 430.233,32 unidades de Argamassa AC1 de 20 kg. A Figura 2 apresenta essa evolução da produção e a Figura 3 apresenta a expectativa de faturamento levando em consideração o menor preço de venda encontrado na pesquisa realizada.

Figura 2: Produção de Argamassa AC1 (Toneladas) - 10 anos com crescimento de 2\% a.a.

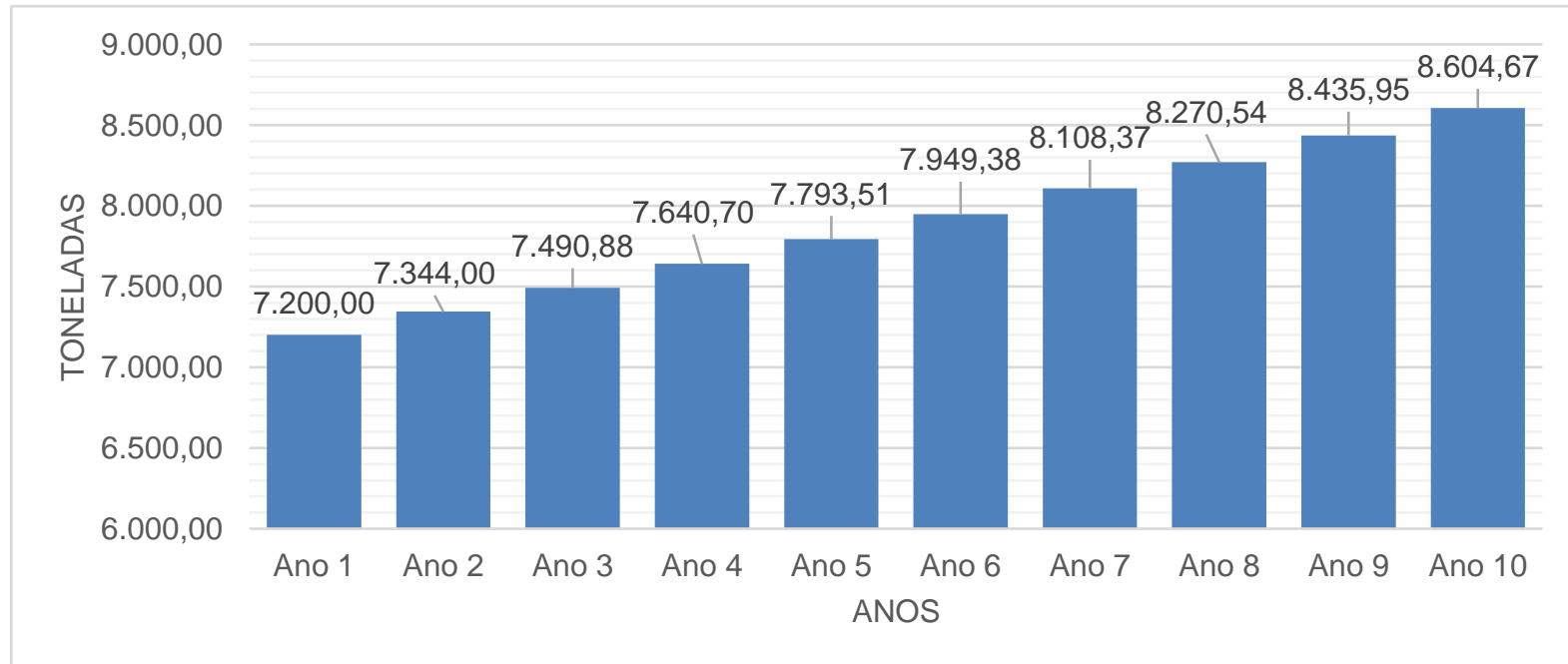

Fonte: Elaborado pelos autores (2020). 
Figura 3: Expectativa de faturamento e um crescimento de $2 \%$ a.a.

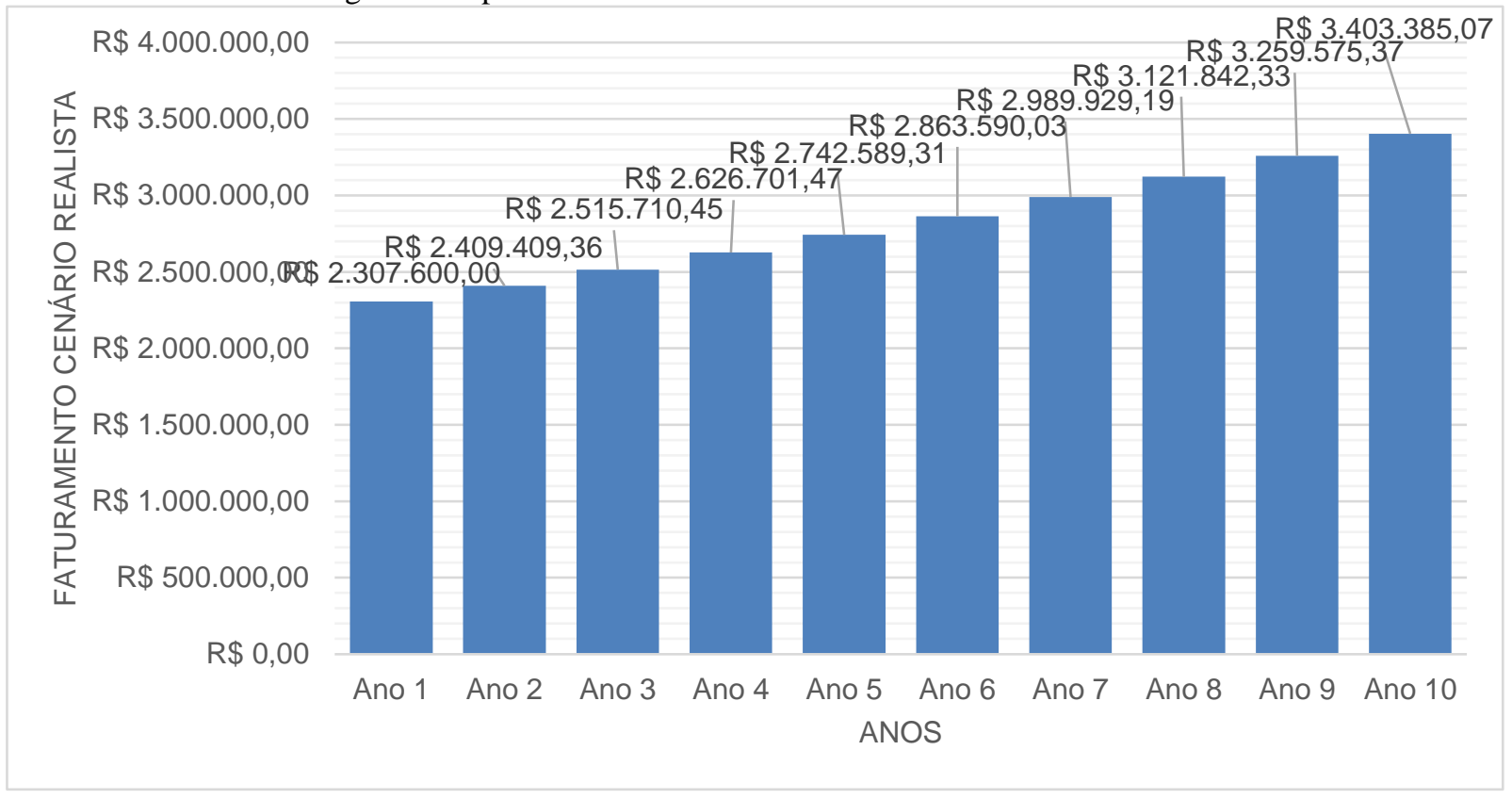

Fonte: Elaborado pelos autores (2020).

\section{- Implantação da Indústria de Argamassa}

Baseando-se na necessidade de atender à demanda levantada e para que não tenha a necessidade de se ter um reinvestimento em relação à ampliação da planta durante os anos projetados de operação, estruturamos um modelo que atenderá às necessidades de produção.

A estrutura de uma indústria de Argamassas apresenta um custo elevado por envolver processos de homogeneização de elementos químicos, em dosagens exatas que garantem qualidade do produto. Há também o armazenamento de matéria prima, que necessita de uma infraestrutura específica para manter a qualidade dos insumos utilizados durante o processo de fabricação da argamassa $\mathrm{AC} 1$, assim, possibilitando que o mesmo concorra com outros produtos similares e de grande destaque no mercado. Também, foi levado em consideração a capacidade de produção da planta industrial. Por ser um produto com baixo valor agregado é necessário que a planta atinja uma produtividade elevada. A atividade também necessita de autorizações de órgãos ambientais, para que possa operar.

Foram levantados os investimentos tanto para área administrativa e licenciamentos quanto para a construção da planta de processamento e empacotamento de argamassa. Os equipamentos terão a capacidade de produtos de até 8.750 toneladas ano do produto que será empacotado em sacos de $20 \mathrm{~kg}$. A indústria utilizará uma área alugada para operar, e contará com uma logística aproximada de alimentação de matéria prima, fornecida pela empresa que 
está anexo, e que será a fornecedora de areia fina. Por ser área do interior do município, a infraestrutura elétrica é precária, entretanto a localização permitiu que tivesse acesso à energia trifásica, pré-requisito para a planta operar não tendo a necessidade de realizar investimento em infraestrutura elétrica. Os equipamentos atenderão as demandas de armazenamento dos insumos, secagem da areia, peneiração da areia, mistura dos materiais primas, dosagem e empacotamento da argamassa, estocagem do produto pronto, carregamento. Os equipamentos necessários para a execução desses processos estão apresentados na Tabela 2.

Tabela 3 - Investimentos para estruturação de uma indústria de argamassas

\begin{tabular}{l|c|r}
\hline Equipamentos & Situação & Valor \\
\hline Silo de Aditivo & Novo & ---------R $\$$---------- \\
\hline Misturador & Novo & $\mathrm{R} \$ 35.000,00$ \\
\hline Empacotador & Novo & $\mathrm{R} \$ 36.600,00$ \\
\hline Esteira da Peneira para o Silo & Novo & $\mathrm{R} \$ 12.500,00$ \\
\hline Silo de Areia & Novo & $\mathrm{R} \$ 35.000,00$ \\
\hline Dosador de Areia & Novo & $\mathrm{R} \$ 25.000,00$ \\
\hline Silo de Cimento & Novo & $\mathrm{R} \$ 35.000,00$ \\
\hline Dosador de Cimento & Novo & $\mathrm{R} \$ 25.000,00$ \\
\hline Empilhadeira & Novo & $\mathrm{R} \$ 89.000,00$ \\
\hline Automóvel Saveiro & Novo & $\mathrm{R} \$ 52.360,00$ \\
\hline $\begin{array}{l}\text { Equipamentos de Tecnologia da Informação e } \\
\text { Comunicação }\end{array}$ & Novo & $\mathrm{R} \$ 5.000,00$ \\
\hline Material para Escritório & Novo & $\mathrm{R} \$ 1.500,00$ \\
\hline Total & & $\mathrm{R} \$ 441.860,00$ \\
\hline
\end{tabular}

Fonte: Elaborado pelos autores (2020).

\section{- Tributação}

A tributação da indústria em questão foi enquadrada conforme o Anexo II Partilhas do Simples Nacional voltada para Indústrias. Como a análise envolve um período de 10 anos e estamos utilizando três cenários a empresa transitará em três faixas do Simples em virtude do aumento do faturamento ao longo do tempo. A Tabela 3 demostra os valores referente as faixar do simples que foram utilizadas nos cálculos.

Tabela 3 - Faixa de impostos do Simples Nacional utilizado na análise

\begin{tabular}{|c|c|c|c|}
\hline Faixa & Faturamento & Alíquota & Valor a Deduzir \\
\hline & ---------------------R\$------------------- & ------\%----- & ---------R\$-------- \\
\hline $4^{\mathrm{a}}$ Faixa & De $720.000,01$ a $1.800 .000,00$ & 11,20 & $22.500,00$ \\
\hline $5^{a}$ Faixa & De $1.800 .000,01$ a $3.600 .000,00$ & 14,70 & $85.500,00$ \\
\hline $6^{\circ}$ Faixa & De $3.600 .000,00$ até $4.800 .000,00$ & 30,00 & $720.000,00$ \\
\hline
\end{tabular}

Fonte: Elaborado pelos autores (2020).

\section{- Estimativa de custos e despesas}


A eficiência na operação e determinação dos fornecedores de insumos se mostrou um fator crítico de sucesso na hora de analisar a viabilidade deste empreendimento. Fatores logísticos e de aquisição de insumos fazem com que a margem do produto seja extinta se não for bem planejada. Foi levantado os custos variáveis para a produção de argamassa, os quais foram estimados com base no traço da argamassa do tipo $\mathrm{AC} 1$ e agrupados os custos diretos e indiretos. A Tabela 4 apresenta o custo variável para produção de Argamassa AC1 apresentada em percentual:

Tabela 4: Composição em \% do custo variável da produção de Argamassa Industrializada

\begin{tabular}{l|c}
\hline Custo & Proporcional a produção \\
\hline Embalagem & 23,30 \\
\hline Materiais (Areia, Cal e Cimento) & 73,59 \\
\hline Energia & 2,59 \\
\hline Diesel & 0,52 \\
\hline Total & $100 \%$ \\
\hline
\end{tabular}

Fonte: Elaborado pelos autores (2020).

Foram levantados os custos fixos necessários para o bom funcionamento da indústria, elencando os principais custos e classificando-os em porcentagem, como apresentado na Tabela 5.

Tabela 5: Composição em \% do Custo Unitário da Argamassa Industrializada

\begin{tabular}{l|r|r}
\hline Custos Fixos & Proporcional dos custos fixos \\
\hline Contabilidade & $\mathrm{R} \$ 380,00$ & $2,4 \%$ \\
\hline Responsável Técnico & $\mathrm{R} \$ 1.000,00$ & $6,3 \%$ \\
\hline Telefone e Internet & $\mathrm{R} \$ 300,00$ & $1,9 \%$ \\
\hline Combustível Gasolina & $\mathrm{R} \$ 500,00$ & $3,1 \%$ \\
\hline Salário Colaboradores da Produção & $\mathrm{R} \$ 3.500,00$ & $22,0 \%$ \\
\hline Encargos e Provisão de Férias $13^{\circ}$ & $\mathrm{R} \$ 1.295,00$ & $8,1 \%$ \\
\hline Salário Administrativo & $\mathrm{R} \$ 1.500,00$ & $9,4 \%$ \\
\hline Encargos e Provisão de Férias $13^{\circ}$ & $\mathrm{R} \$ 555,00$ & $3,5 \%$ \\
\hline Pró-labore & $\mathrm{R} \$ 2.500,00$ & $15,7 \%$ \\
\hline Encargos e Provisão de Férias $13^{\circ}$ & $\mathrm{R} \$ 925,00$ & $5,8 \%$ \\
\hline Licenciamentos e Alvarás de Funcionamento & $\mathrm{R} \$ 200,00$ & $1,3 \%$ \\
\hline Tarifas Conta PJ & $\mathrm{R} \$ 50,00$ & $0,3 \%$ \\
\hline Água & $\mathrm{R} \$ 50,00$ & $0,3 \%$ \\
\hline Energia & $\mathrm{R} \$ 50,00$ & $0,3 \%$ \\
\hline Sistema & $\mathrm{R} \$ 80,00$ & $0,5 \%$ \\
\hline Locação & $\mathrm{R} \$ 1.850,00$ & $11,6 \%$ \\
\hline Manutenções Preventivas & $\mathrm{R} \$ 1.200,00$ & $7,5 \%$ \\
\hline Total & & $100 \%$ \\
\hline
\end{tabular}

Fonte: Elaborado pelos autores (2020). 
Após o levantamento das informações, compondo valor total a ser investido, custo do produto a ser vendido e preço de venda a ser praticado em cada cenário, foram feitas análises, tendo como definição os cenários pessimista, realista e otimista. A variação de preço de venda da Argamassa AC1 e o investimento inicial é o que diferencia os cenários descritos na Tabela 6.

Tabela 6 - Cenários

\begin{tabular}{l|c|c|c|c}
\hline Cenários & Pessimista & Realista & Otimista & \\
\hline Período analisado & 10 anos & 10 anos & 10 anos & \\
\hline Investimento Inicial & $\mathrm{R} \$ 589.211,86$ & $\mathrm{R} \$ 594.865,48$ & $\mathrm{R} \$ 587.618,69$ & \\
\hline TMA & $14,13 \%$ & $14,13 \%$ & $14,13 \%$ & \\
\hline Produção em Toneladas & $78.837,990$ & $78.837,99$ & $78.837,99$ & \\
\hline Preço de Inicial & $\mathrm{R} \$ 5,13$ & $\mathrm{R} \$ 6,41$ & $\mathrm{R} \$ 8,08$ & \\
\hline VPL & $-\mathrm{R} \$ 28.816,81$ & $\mathrm{R} \$ 3.507 .589,14$ & $\mathrm{R} \$ 27.471 .627,29$ & \\
\hline TIR & $13,17 \%$ & $81,34 \%$ & $200,30 \%$ & \\
\hline Payback descontado & Acima de 10 anos & 1,53 & 1,07 & \\
\hline IL & 0,9511 & 4,8964 & 45,7508 & \\
\hline
\end{tabular}

Fonte: Elaborado pelos autores (2020).

\section{- Cenário pessimista}

Nesse cenário segundo o fluxo de caixa apresentado na Tabela 7, apresentamos uma produção de 78.837,99 toneladas em 10 anos, preço inicial de venda $\mathrm{R} \$ 5,13$ de venda e preço médio R \$ 5,71 apresentamos os seguintes indicadores, Valor Presente Líquido (VPL) negativo em -R \$28.816,81, Taxa Interna de Retorno (TIR) de 13,17\%, Payback descontado acima de 10 anos e índice de lucratividade 0,9511 .

\section{- Cenário realista}

Nesse cenário segundo o fluxo de caixa apresentado na Tabela 8, apresentamos uma produção de 78.837,99 toneladas em 10 anos, preço inicial de venda $\mathrm{R} \$ 6,41$ de venda e preço médio $\mathrm{R} \$ 7,14$ apresentamos os seguintes indicadores, Valor Presente Líquido (VPL) positivo em R 3.507.589,14, Taxa Interna de Retorno (TIR) de 81,34\%, Payback descontado em 1,6 anos e índice de lucratividade 4,89.

\section{- Cenário otimista}

Nesse cenário segundo o fluxo de caixa apresentado na Tabela 9, apresentamos uma produção de 78.837,99 toneladas em 10 anos, preço inicial de venda $\mathrm{R} \$ 8,08$ de venda e preço médio R \$9,00 apresentamos os seguintes indicadores, Valor Presente Líquido (VPL) positivo em R \$ 27.471.627,29, Taxa Interna de Retorno (TIR) de 200,30\%, Payback descontado em 1,1 anos e índice de lucratividade 45,75. 
Tabela 7: Fluxo de Caixa (Cenário Pessimista)

\begin{tabular}{|c|c|c|c|c|c|c|}
\hline Ano & 0 & 1 & 2 & 3 & 4 & 5 \\
\hline Investimento Planta & $\mathrm{R} \$ 441.860,00$ & & & & & \\
\hline Receita Bruta & & $\mathrm{R} \$ 1.846 .080,00$ & $\mathrm{R} \$ 1.927 .527,48$ & $\mathrm{R} \$ 2.012 .568,36$ & $\mathrm{R} \$ 2.101 .361,17$ & $\mathrm{R} \$ 2.194 .071,45$ \\
\hline Simples Nacional & & $\mathrm{R} \$ 186.373,76$ & $\mathrm{R} \$ 198.346,54$ & $\mathrm{R} \$ 210.847,55$ & $\mathrm{R} \$ 223.900,09$ & $\mathrm{R} \$ 237.528,50$ \\
\hline Receita Liquida & & $\mathrm{R} \$ 1.659 .706,24$ & $\mathrm{R} \$ 1.729 .180,94$ & $\mathrm{R} \$ 1.801 .720,81$ & $\mathrm{R} \$ 1.877 .461,08$ & $\mathrm{R} \$ 1.956 .542,95$ \\
\hline Custo do produto vendido & & $\mathrm{R} \$ 1.390 .628,57$ & $\mathrm{R} \$ 1.451 .981,93$ & $\mathrm{R} \$ 1.516 .042,14$ & $\mathrm{R} \$ 1.582 .928,63$ & $\mathrm{R} \$ 1.652 .766,10$ \\
\hline Lucro Bruto & & $\mathrm{R} \$ 269.077,67$ & $\mathrm{R} \$ 277.199,02$ & $\mathrm{R} \$ 285.678,68$ & $\mathrm{R} \$ 294.532,45$ & $\mathrm{R} \$ 303.776,84$ \\
\hline Despesas Administrativas & & $\mathrm{R} \$ 191.220,00$ & $\mathrm{R} \$ 195.656,30$ & $\mathrm{R} \$ 200.195,53$ & $\mathrm{R} \$ 204.840,07$ & $\mathrm{R} \$ 209.592,36$ \\
\hline Depreciação & & $\mathrm{R} \$ 49.026,68$ & $\mathrm{R} \$ 49.026,68$ & $\mathrm{R} \$ 49.026,68$ & $\mathrm{R} \$ 49.026,68$ & $\mathrm{R} \$ 49.026,68$ \\
\hline Lucro Líquido & & $\mathrm{R} \$ 28.830,98$ & $\mathrm{R} \$ 32.516,03$ & $\mathrm{R} \$ 36.456,46$ & $\mathrm{R} \$ 40.665,70$ & $\mathrm{R} \$ 45.157,80$ \\
\hline Depreciação & & $\mathrm{R} \$ 49.026,68$ & $\mathrm{R} \$ 49.026,68$ & $\mathrm{R} \$ 49.026,68$ & $\mathrm{R} \$ 49.026,68$ & $\mathrm{R} \$ 49.026,68$ \\
\hline Lucro/Prejuízo & $-\mathrm{R} \$ 441.860,00$ & $\mathrm{R} \$ 77.857,67$ & $\mathrm{R} \$ 81.542,72$ & $\mathrm{R} \$ 85.483,15$ & $\mathrm{R} \$ 89.692,38$ & $\mathrm{R} \$ 94.184,49$ \\
\hline $\begin{array}{l}\text { Necessidade de Capital de Giro } \\
\text { (Crescimento 2\%) }\end{array}$ & $-\mathrm{R} \$ 147.351,86$ & $-\mathrm{R} \$ 6.480,20$ & $-\mathrm{R} \$ 6.758,37$ & $-\mathrm{R} \$ 7.048,63$ & $-\mathrm{R} \$ 7.351,51$ & $-\mathrm{R} \$ 7.667,57$ \\
\hline Fluxo de Caixa & $-\mathrm{R} \$ 589.211,86$ & $\mathrm{R} \$ 71.377,47$ & $\mathrm{R} \$ 74.784,34$ & $\mathrm{R} \$ 78.434,52$ & $\mathrm{R} \$ 82.340,87$ & $\mathrm{R} \$ 86.516,92$ \\
\hline Fluxo de Caixa Acumulado & $-\mathrm{R} \$ 589.211,86$ & $-\mathrm{R} \$ 517.834,40$ & $\mathrm{R} \$ 146.161,81$ & $\mathrm{R} \$ 153.218,86$ & $\mathrm{R} \$ 160.775,39$ & $\mathrm{R} \$ 168.857,79$ \\
\hline Fluxo de Caixa Descontado & $-\mathrm{R} \$ 589.211,86$ & $\mathrm{R} \$ 62.540,49$ & $\mathrm{R} \$ 57.413,11$ & $\mathrm{R} \$ 52.760,36$ & $\mathrm{R} \$ 48.530,66$ & $\mathrm{R} \$ 44.678,85$ \\
\hline $\begin{array}{l}\text { Fluxo de Caixa Acumulado } \\
\text { Descontado }\end{array}$ & $-\mathrm{R} \$ 589.211,86$ & $-\mathrm{R} \$ 526.671,37$ & $-\mathrm{R} \$ 469.258,26$ & $-\mathrm{R} \$ 416.497,90$ & $-\mathrm{R} \$ 367.967,24$ & $-\mathrm{R} \$ 323.288,39$ \\
\hline
\end{tabular}




\begin{tabular}{|c|c|c|c|c|c|}
\hline Ano & 6 & 7 & 8 & 9 & 10 \\
\hline \multicolumn{6}{|l|}{ Investimento Planta } \\
\hline Receita Bruta & $\mathrm{R} \$ 2.290 .872,02$ & $\mathrm{R} \$ 2.391 .943,35$ & $\mathrm{R} \$ 2.497 .473,87$ & $\mathrm{R} \$ 2.607 .660,30$ & $\mathrm{R} \$ 2.722 .708,06$ \\
\hline Simples Nacional & $\mathrm{R} \$ 251.758,19$ & $\mathrm{R} \$ 266.615,67$ & $\mathrm{R} \$ 282.128,66$ & $\mathrm{R} \$ 298.326,06$ & $\mathrm{R} \$ 315.238,08$ \\
\hline Receita Liquida & $\mathrm{R} \$ 2.039 .113,83$ & $\mathrm{R} \$ 2.125 .327,68$ & $\mathrm{R} \$ 2.215 .345,21$ & $\mathrm{R} \$ 2.309 .334,23$ & $\mathrm{R} \$ 2.407 .469,97$ \\
\hline Custo do produto vendido & $\mathrm{R} \$ 1.725 .684,74$ & $\mathrm{R} \$ 1.801 .820,49$ & $\mathrm{R} \$ 1.881 .315,28$ & $\mathrm{R} \$ 1.964 .317,32$ & $\mathrm{R} \$ 2.050 .981,33$ \\
\hline Lucro Bruto & $\mathrm{R} \$ 313.429,09$ & $\mathrm{R} \$ 323.507,19$ & $\mathrm{R} \$ 334.029,93$ & $\mathrm{R} \$ 345.016,92$ & $\mathrm{R} \$ 356.488,64$ \\
\hline Despesas Administrativas & $\mathrm{R} \$ 214.454,90$ & $\mathrm{R} \$ 219.430,25$ & $\mathrm{R} \$ 224.521,03$ & $\mathrm{R} \$ 229.729,92$ & $\mathrm{R} \$ 235.059,66$ \\
\hline Depreciação & $\mathrm{R} \$ 49.026,68$ & $\mathrm{R} \$ 49.026,68$ & $\mathrm{R} \$ 49.026,68$ & $\mathrm{R} \$ 49.026,68$ & $\mathrm{R} \$ 49.026,68$ \\
\hline Lucro Líquido & $\mathrm{R} \$ 49.947,51$ & $\mathrm{R} \$ 55.050,25$ & $\mathrm{R} \$ 60.482,21$ & $\mathrm{R} \$ 66.260,31$ & $\mathrm{R} \$ 72.402,30$ \\
\hline Depreciação & $\mathrm{R} \$ 49.026,68$ & $\mathrm{R} \$ 49.026,68$ & $\mathrm{R} \$ 49.026,68$ & $\mathrm{R} \$ 49.026,68$ & $\mathrm{R} \$ 49.026,68$ \\
\hline Lucro/Prejuízo & $\mathrm{R} \$ 98.974,19$ & $\mathrm{R} \$ 104.076,94$ & $\mathrm{R} \$ 109.508,89$ & $\mathrm{R} \$ 115.286,99$ & $\mathrm{R} \$ 338.202,24$ \\
\hline $\begin{array}{l}\text { Necessidade de Capital de Giro } \\
\text { (Crescimento 2\%) }\end{array}$ & $-\mathrm{R} \$ 7.997,38$ & $-\mathrm{R} \$ 8.341,55$ & $-\mathrm{R} \$ 8.700,69$ & $-\mathrm{R} \$ 9.075,48$ & $\mathrm{R} \$ 216.773,26$ \\
\hline Fluxo de Caixa & $\mathrm{R} \$ 90.976,81$ & $\mathrm{R} \$ 95.735,39$ & $\mathrm{R} \$ 100.808,20$ & $\mathrm{R} \$ 106.211,51$ & $\mathrm{R} \$ 554.975,50$ \\
\hline Fluxo de Caixa Acumulado & $\mathrm{R} \$ 177.493,73$ & $\mathrm{R} \$ 186.712,20$ & $\mathrm{R} \$ 196.543,59$ & $\mathrm{R} \$ 207.019,71$ & $\mathrm{R} \$ 661.187,01$ \\
\hline Fluxo de Caixa Descontado & $\mathrm{R} \$ 41.165,35$ & $\mathrm{R} \$ 37.955,42$ & $\mathrm{R} \$ 35.018,48$ & $\mathrm{R} \$ 32.327,58$ & $\mathrm{R} \$ 148.004,74$ \\
\hline Fluxo de Caixa Acumulado Descontado & $-\mathrm{R} \$ 282.123,04$ & $-\mathrm{R} \$ 244.167,62$ & $-\mathrm{R} \$ 209.149,14$ & $-\mathrm{R} \$ 176.821,56$ & $-\mathrm{R} \$ 28.816,81$ \\
\hline Fonte: Elaborado pelos autores (2020). & & & & & \\
\hline
\end{tabular}


Tabela 8: Fluxo de Caixa (Cenário Realista)

\begin{tabular}{|c|c|c|c|c|c|c|}
\hline Ano & 0 & 1 & 2 & 3 & 4 & 5 \\
\hline Investimento + Capital de Giro & $\mathrm{R} \$ 441.860,00$ & $\mathrm{R} \$ 0,00$ & $\mathrm{R} \$ 0,00$ & $\mathrm{R} \$ 0,00$ & $\mathrm{R} \$ 0,00$ & $\mathrm{R} \$ 0,00$ \\
\hline Receita Bruta & & $\mathrm{R} \$ 2.307 .600,00$ & $\mathrm{R} \$ 2.409 .409,36$ & $\mathrm{R} \$ 2.515 .710,45$ & $\mathrm{R} \$ 2.626 .701,47$ & $\mathrm{R} \$ 2.742 .589,31$ \\
\hline Simples Nacional & & $\mathrm{R} \$ 254.217,20$ & $\mathrm{R} \$ 269.183,18$ & $\mathrm{R} \$ 284.809,44$ & $\mathrm{R} \$ 301.125,12$ & $\mathrm{R} \$ 318.160,63$ \\
\hline Receita Liquida & & $\mathrm{R} \$ 2.053 .382,80$ & $\mathrm{R} \$ 2.140 .226,18$ & $\mathrm{R} \$ 2.230 .901,02$ & $\mathrm{R} \$ 2.325 .576,35$ & $\mathrm{R} \$ 2.424 .428,68$ \\
\hline Custo do produto vendido & & $\mathrm{R} \$ 1.390 .628,57$ & $\mathrm{R} \$ 1.451 .981,93$ & $\mathrm{R} \$ 1.516 .042,14$ & $\mathrm{R} \$ 1.582 .928,63$ & $\mathrm{R} \$ 1.652 .766,10$ \\
\hline Lucro Bruto & & $\mathrm{R} \$ 662.754,23$ & $\mathrm{R} \$ 688.244,26$ & $\mathrm{R} \$ 714.858,88$ & $\mathrm{R} \$ 742.647,72$ & $\mathrm{R} \$ 771.662,58$ \\
\hline Despesas Administrativas & & $\mathrm{R} \$ 191.220,00$ & $\mathrm{R} \$ 195.656,30$ & $\mathrm{R} \$ 200.195,53$ & $\mathrm{R} \$ 204.840,07$ & $\mathrm{R} \$ 209.592,36$ \\
\hline Depreciação & & $\mathrm{R} \$ 49.026,68$ & $\mathrm{R} \$ 49.026,68$ & $\mathrm{R} \$ 49.026,68$ & $\mathrm{R} \$ 49.026,68$ & $\mathrm{R} \$ 49.026,68$ \\
\hline Lucro Líquido & & $\mathrm{R} \$ 422.507,54$ & $\mathrm{R} \$ 443.561,27$ & $\mathrm{R} \$ 465.636,67$ & $\mathrm{R} \$ 488.780,97$ & $\mathrm{R} \$ 513.043,54$ \\
\hline Depreciação & & $\mathrm{R} \$ 49.026,68$ & $\mathrm{R} \$ 49.026,68$ & $\mathrm{R} \$ 49.026,68$ & $\mathrm{R} \$ 49.026,68$ & $\mathrm{R} \$ 49.026,68$ \\
\hline Lucro/Prejuízo & $-\mathrm{R} \$ 441.860,00$ & $\mathrm{R} \$ 464.804,59$ & $\mathrm{R} \$ 485.569,14$ & $\mathrm{R} \$ 507.342,79$ & $\mathrm{R} \$ 530.172,21$ & $\mathrm{R} \$ 554.106,20$ \\
\hline Capital de Giro & $-\mathrm{R} \$ 153.005,48$ & $-\mathrm{R} \$ 6.729,64$ & $-\mathrm{R} \$ 7.018,81$ & $-\mathrm{R} \$ 7.320,56$ & $-\mathrm{R} \$ 7.635,44$ & -R\$ 7.964,02 \\
\hline Fluxo de Caixa & $-\mathrm{R} \$ 594.865,48$ & $\mathrm{R} \$ 458.074,96$ & $\mathrm{R} \$ 478.550,33$ & $\mathrm{R} \$ 500.022,23$ & $\mathrm{R} \$ 522.536,78$ & $\mathrm{R} \$ 546.142,18$ \\
\hline Fluxo de Caixa Acumulado & $-\mathrm{R} \$ 594.865,48$ & $\mathrm{R} \$ 458.074,96$ & $\mathrm{R} \$ 936.625,29$ & $\mathrm{R} \$ 1.436 .647,52$ & $\mathrm{R} \$ 1.959 .184,30$ & $\mathrm{R} \$ 2.505 .326,48$ \\
\hline Fluxo de Caixa Descontado & $-\mathrm{R} \$ 594.865,48$ & $\mathrm{R} \$ 401.362,44$ & $\mathrm{R} \$ 367.390,56$ & $\mathrm{R} \$ 336.348,78$ & $\mathrm{R} \$ 307.976,51$ & $\mathrm{R} \$ 282.037,35$ \\
\hline Fluxo de Caixa Acumulado Descontado & $-\mathrm{R} \$ 594.865,48$ & $-\mathrm{R} \$ 193.503,04$ & $\mathrm{R} \$ 173.887,52$ & $\mathrm{R} \$ 510.236,30$ & $\mathrm{R} \$ 818.212,81$ & $\mathrm{R} \$ 1.100 .250,17$ \\
\hline
\end{tabular}




\begin{tabular}{|c|c|c|c|c|c|}
\hline Ano & 6 & 7 & 8 & 9 & 10 \\
\hline Investimento + Capital de Giro & $\mathrm{R} \$ 0,00$ & $\mathrm{R} \$ 0,00$ & $\mathrm{R} \$ 0,00$ & $\mathrm{R} \$ 0,00$ & $\mathrm{R} \$ 0,00$ \\
\hline Receita Bruta & $\mathrm{R} \$ 2.863 .590,03$ & $\mathrm{R} \$ 2.989 .929,19$ & $\mathrm{R} \$ 3.121 .842,33$ & $\mathrm{R} \$ 3.259 .575,37$ & $\mathrm{R} \$ 3.403 .385,07$ \\
\hline Simples Nacional & $\mathrm{R} \$ 335.947,73$ & $\mathrm{R} \$ 354.519,59$ & $\mathrm{R} \$ 373.910,82$ & $\mathrm{R} \$ 394.157,58$ & $\mathrm{R} \$ 415.297,61$ \\
\hline Receita Liquida & $\mathrm{R} \$ 2.527 .642,29$ & $\mathrm{R} \$ 2.635 .409,60$ & $\mathrm{R} \$ 2.747 .931,51$ & $\mathrm{R} \$ 2.865 .417,79$ & $\mathrm{R} \$ 2.988 .087,47$ \\
\hline Custo do produto vendido & $\mathrm{R} \$ 1.725 .684,74$ & $\mathrm{R} \$ 1.801 .820,49$ & $\mathrm{R} \$ 1.881 .315,28$ & $\mathrm{R} \$ 1.964 .317,32$ & $\mathrm{R} \$ 2.050 .981,33$ \\
\hline Lucro Bruto & $\mathrm{R} \$ 801.957,55$ & $\mathrm{R} \$ 833.589,11$ & $\mathrm{R} \$ 866.616,23$ & $\mathrm{R} \$ 901.100,47$ & $\mathrm{R} \$ 937.106,14$ \\
\hline Despesas Administrativas & $\mathrm{R} \$ 214.454,90$ & $\mathrm{R} \$ 219.430,25$ & $\mathrm{R} \$ 224.521,03$ & $\mathrm{R} \$ 229.729,92$ & $\mathrm{R} \$ 235.059,66$ \\
\hline Depreciação & $\mathrm{R} \$ 49.026,68$ & $\mathrm{R} \$ 49.026,68$ & $\mathrm{R} \$ 49.026,68$ & $\mathrm{R} \$ 49.026,68$ & $\mathrm{R} \$ 49.026,68$ \\
\hline Lucro Líquido & $\mathrm{R} \$ 538.475,97$ & $\mathrm{R} \$ 565.132,17$ & $\mathrm{R} \$ 593.068,51$ & $\mathrm{R} \$ 622.343,87$ & $\mathrm{R} \$ 653.019,79$ \\
\hline Depreciação & $\mathrm{R} \$ 49.026,68$ & $\mathrm{R} \$ 49.026,68$ & $\mathrm{R} \$ 49.026,68$ & $\mathrm{R} \$ 49.026,68$ & $\mathrm{R} \$ 49.026,68$ \\
\hline Lucro/Prejuízo & $\mathrm{R} \$ 579.195,74$ & $\mathrm{R} \$ 605.494,12$ & $\mathrm{R} \$ 633.057,05$ & $\mathrm{R} \$ 661.942,74$ & $\mathrm{R} \$ 927.158,03$ \\
\hline Capital de Giro & -R\$ 8.306,91 & $-\mathrm{R} \$ 8.664,73$ & $-\mathrm{R} \$ 9.038,14$ & -R\$9.427,81 & $\mathrm{R} \$ 225.111,55$ \\
\hline Fluxo de Caixa & $\mathrm{R} \$ 570.888,83$ & $\mathrm{R} \$ 596.829,39$ & $\mathrm{R} \$ 624.018,91$ & $\mathrm{R} \$ 652.514,92$ & $\mathrm{R} \$ 1.152 .269,58$ \\
\hline Fluxo de Caixa Acumulado & $\mathrm{R} \$ 3.076 .215,30$ & $\mathrm{R} \$ 3.673 .044,69$ & $\mathrm{R} \$ 4.297 .063,61$ & $\mathrm{R} \$ 4.949 .578,53$ & $\mathrm{R} \$ 6.101 .848,11$ \\
\hline Fluxo de Caixa Descontado & $\mathrm{R} \$ 258.316,79$ & $\mathrm{R} \$ 236.620,02$ & $\mathrm{R} \$ 216.770,02$ & $\mathrm{R} \$ 198.605,88$ & $\mathrm{R} \$ 307.295,30$ \\
\hline Fluxo de Caixa Acumulado Descontado & $\mathrm{R} \$ 1.358 .566,96$ & $\mathrm{R} \$ 1.595 .186,98$ & $\mathrm{R} \$ 1.811 .956,99$ & $\mathrm{R} \$ 2.010 .562,87$ & $\mathrm{R} \$ 2.317 .858,17$ \\
\hline
\end{tabular}

Fonte: Elaborado pelos autores (2020). 
Tabela 9: Fluxo de Caixa (Cenário Otimista)

\begin{tabular}{|c|c|c|c|c|c|c|}
\hline Ano & 0 & 1 & 2 & 3 & 4 & 5 \\
\hline Investimento + Capital de Giro & $\mathrm{R} \$ 441.860,00$ & & & & & \\
\hline Receita Bruta & & $\mathrm{R} \$ 2.908 .440,00$ & $\mathrm{R} \$ 3.036 .757,91$ & $\mathrm{R} \$ 3.170 .737,09$ & $\mathrm{R} \$ 3.310 .627,33$ & $\mathrm{R} \$ 3.456 .689,40$ \\
\hline Simples Nacional & & $\mathrm{R} \$ 342.540,68$ & $\mathrm{R} \$ 361.403,41$ & $\mathrm{R} \$ 381.098,35$ & $\mathrm{R} \$ 401.662,22$ & $\mathrm{R} \$ 423.133,34$ \\
\hline Receita Liquida & & $\mathrm{R} \$ 2.565 .899,32$ & $\mathrm{R} \$ 2.675 .354,50$ & $\mathrm{R} \$ 2.789 .638,74$ & $\mathrm{R} \$ 2.908 .965,11$ & $\mathrm{R} \$ 3.033 .556,06$ \\
\hline Custo do produto vendido & & $\mathrm{R} \$ 1.390 .628,57$ & $\mathrm{R} \$ 1.451 .981,93$ & $\mathrm{R} \$ 1.516 .042,14$ & $\mathrm{R} \$ 1.582 .928,63$ & $\mathrm{R} \$ 1.652 .766,10$ \\
\hline Lucro Bruto & & $\mathrm{R} \$ 1.175 .270,75$ & $\mathrm{R} \$ 1.223 .372,57$ & $\mathrm{R} \$ 1.273 .596,60$ & $\mathrm{R} \$ 1.326 .036,48$ & $\mathrm{R} \$ 1.380 .789,96$ \\
\hline Despesas Administrativas & & $\mathrm{R} \$ 15.935,00$ & $\mathrm{R} \$ 16.304,69$ & $\mathrm{R} \$ 16.682,96$ & $\mathrm{R} \$ 17.070,01$ & $\mathrm{R} \$ 17.466,03$ \\
\hline Depreciação & & $\mathrm{R} \$ 49.026,68$ & $\mathrm{R} \$ 49.026,68$ & $\mathrm{R} \$ 49.026,68$ & $\mathrm{R} \$ 49.026,68$ & $\mathrm{R} \$ 49.026,68$ \\
\hline Lucro Líquido & & $\mathrm{R} \$ 1.110 .309,06$ & $\mathrm{R} \$ 1.158 .041,19$ & $\mathrm{R} \$ 1.207 .886,96$ & $\mathrm{R} \$ 1.259 .939,79$ & $\mathrm{R} \$ 1.314 .297,24$ \\
\hline Depreciação & & $\mathrm{R} \$ 49.026,68$ & $\mathrm{R} \$ 49.026,68$ & $\mathrm{R} \$ 49.026,68$ & $\mathrm{R} \$ 49.026,68$ & $\mathrm{R} \$ 49.026,68$ \\
\hline Lucro/Prejuízo & $-\mathrm{R} \$ 441.860,00$ & $\mathrm{R} \$ 1.159 .335,75$ & $\mathrm{R} \$ 1.207 .067,88$ & $\mathrm{R} \$ 1.256 .913,64$ & $\mathrm{R} \$ 1.308 .966,47$ & $\mathrm{R} \$ 1.363 .323,93$ \\
\hline Capital de Giro & $-\mathrm{R} \$ 145.758,69$ & $-\mathrm{R} \$ 6.715,48$ & $-\mathrm{R} \$ 7.011,12$ & $-\mathrm{R} \$ 7.319,78$ & $-\mathrm{R} \$ 7.642,05$ & $-\mathrm{R} \$ 1.079,10$ \\
\hline Fluxo de Caixa & $-\mathrm{R} \$ 587.618,69$ & $\mathrm{R} \$ 1.152 .620,27$ & $\mathrm{R} \$ 1.200 .056,76$ & $\mathrm{R} \$ 1.249 .593,86$ & $\mathrm{R} \$ 1.301 .324,42$ & $\mathrm{R} \$ 1.362 .244,83$ \\
\hline Fluxo de Caixa Acumulado & $-\mathrm{R} \$ 587.618,69$ & $\mathrm{R} \$ 565.001,58$ & $\mathrm{R} \$ 1.765 .058,34$ & $\mathrm{R} \$ 3.014 .652,20$ & $\mathrm{R} \$ 4.315 .976,62$ & $\mathrm{R} \$ 5.678 .221,44$ \\
\hline Fluxo de Caixa Descontado & $-\mathrm{R} \$ 587.618,69$ & $\mathrm{R} \$ 495.050,89$ & $\mathrm{R} \$ 1.355 .062,82$ & $\mathrm{R} \$ 2.027 .859,04$ & $\mathrm{R} \$ 2.543 .781,56$ & $\mathrm{R} \$ 2.932 .332,67$ \\
\hline Fluxo de Caixa Acumulado Descontado & $-\mathrm{R} \$ 587.618,69$ & $-\mathrm{R} \$ 92.567,80$ & $\mathrm{R} \$ 1.262 .495,02$ & $\mathrm{R} \$ 3.290 .354,06$ & $\mathrm{R} \$ 5.834 .135,62$ & $\mathrm{R} \$ 8.766 .468,29$ \\
\hline
\end{tabular}




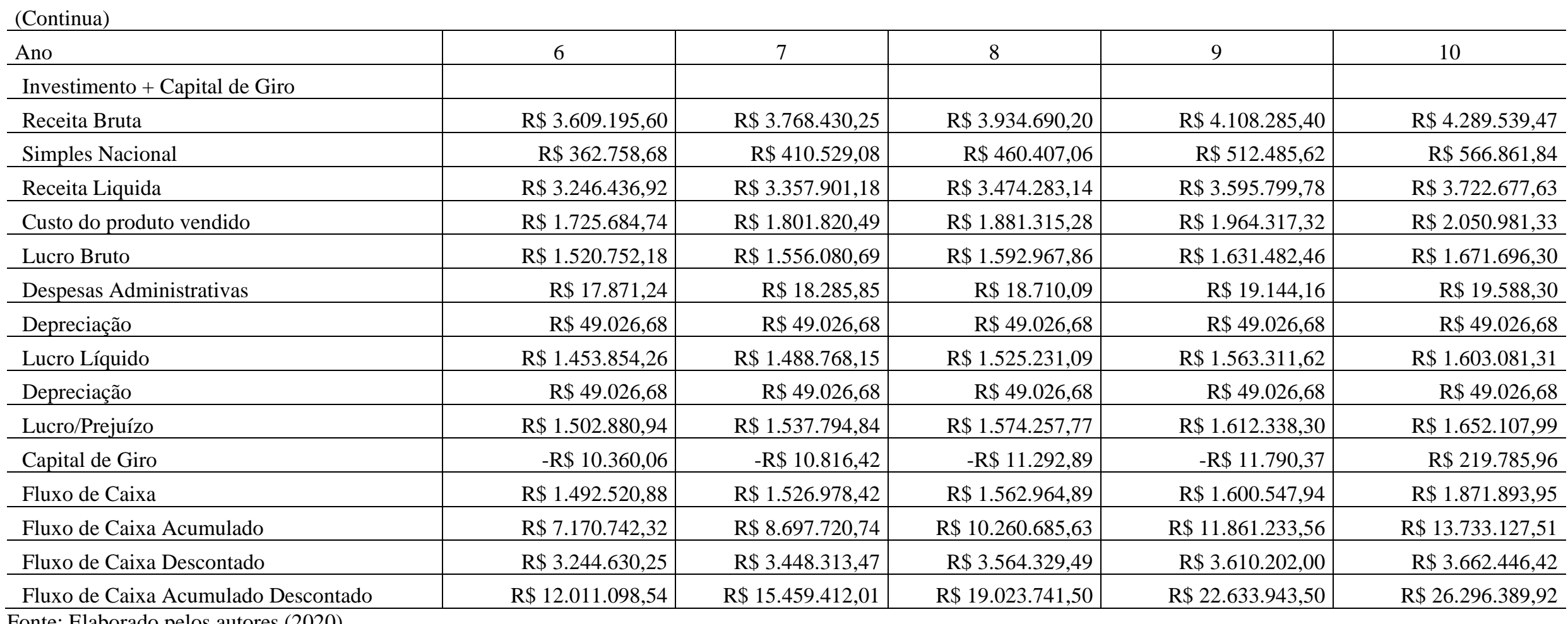




\section{CONSIDERAÇÕES FINAIS}

O objetivo deste artigo foi analisar a viabilidade econômica e financeira de uma indústria de argamassas. Para lograr esse objetivo foram utilizados alguns indicadores que tinham o intuito de evidenciar se o projeto de negócio seria viável ou não. E com os valores obtidos desses índices foram construídos 3 cenários de viabilidade do projeto e posteriormente esses cenários foram analisados.

A análise realizada apresentou um VPL positivo no cenário Realista e no cenário otimista, a Taxa Mínima de Atratividade fixada em 14,13\%, indicando que o projeto com essa taxa no cenário realista e otimista é capaz de garantir a remuneração do capital do investidor, nesse sentido, tornando-se economicamente viável. Ou seja, dentro de um cenário negativo, o projeto torna-se inviável para se investir.

Assim sendo, de acordo com os valores advindos com base no Payback descontado, atingiu-se em apenas um cenário (negativo) um retorno do capital acima de 10 anos de operação. De modo que, os cenários realista e otimista apresentam um retorno do capital abaixo de 2 anos de projeto.

\section{REFERÊNCIAS}

Assaf Neto, A. (2020). Administração de Capital de Giro. $3^{\text {a }}$ ed.. São Paulo: Atlas.

Assaf Neto, A. (2014). Finanças Corporativas e Valor. $7^{\text {a }}$ ed.. São Paulo: Atlas.

Associação Brasileira de Argamassas Industrializadas - ABAI. Mercado. (2015). Recuperado de: https://abai.org.br/mercados/.

Associação Brasileira da Construção Industrializada de Concreto - ABCIC. (2020). Faturamento de Indústrias da Construção Civil deve cair mais de 10\%. Recuperado de: https://www.abcic.org.br/Noticia/Exibir/faturamento-de-industrias-da-construcao-civil-devecair-mais-de-10

Bardin, L. (2011). Análise de Conteúdo. São Paulo: Edições 70.

Bruni, A. L. \& Famá, R. (2008) As Decisões de Investimentos - Com aplicações na HP12C e Excel. 3 ed. São Paulo: Atlas.

Banco Nacional do Desenvolvimento Econômico e Social - BNDES. (2020). Simulação de Financiamento. 
(2020). Pessoa jurídica - Capital de giro com prazo superior a 365 dias. Recuperado de: https://www.bcb.gov.br/estatisticas/reporttxju ros?path=conteudo Ftxcred\%2FReports\%2FTaxasCredito-Consolidadas-por TaxasAnuais.rdl\&n ome=Pessoa \%20jur\%C3\%ADdica\%20-\%20Capital\%20de\%20giro\%20com\%20prazo\%20super io r\%2 0a\%20365\%20dias\&parametros=tipopessoa:2;modalidade:211;encar go :101\&exi be p a r ametros $=$ false $\&$ exibe paginacao $=$ false

Dornelas, J. C. A. (2016). Plano de negócios: seu guia definitivo: o passo a passo para você planejar e criar um negócio de sucesso. 2 ed. São Paulo: Empreende.

Federação das Indústrias do Estado de Santa Catarina - FIESC. (2020). Reformas abrem espaço para crescimento maior em 2020. Recuperado de: https://fiesc.com.br/ptbr/imprensa/reformas-abrem-espaco-para-crescimento-maior-em-2020.

Gil, A. C. (2002). Como Elaborar Projetos de Pesquisa. 4 ed. São Paulo: Atlas.

Gil, A. C. (2010). Métodos e técnicas de pesquisa social. 6 ed. São Paulo: Atlas.

Malhotra, N. (2001). Pesquisa de Marketing. 3 ed. Porto Alegre: Bookman.

Mundo Financeiro. (2017). TMA - Taxa Mínima de Atratividade. Recuperado de: https://www.mundofinanceiro.com.br/taxa-minima-de-atratividade/

Richardson, R. J. (1999). Pesquisa social: métodos e técnicas. 3 ed. São Paulo: Atlas.

Receita Federal do Brasil - RFB. (2020). O que é Simples Nacional. Recuperado de: http://www8.receita.fazenda.gov.br/SimplesNacional/Documentos/Pagina.aspx?id=3

Receita Federal do Brasil - RFB. (2020). (2020). Simples Nacional Anexo II - Industrias. Recuperado de: http://normas.receita.fazenda.gov.br/sijut2consulta/anexoOutros.action?idArquivoBinario=48 $\underline{431}$

Rêgo, R. B., Paulo, G. P., Spritzer, I. M. P. A. \& Zotoes, L. P.(2015). Viabilidade econômicofinanceira de projetos. 4 ed. São Paulo: FGV.

Serviço Brasileiro de Apoio às Micro e Pequenas Empresas - SEBRAE. (2011). Como montar uma fábrica de argamassas e rejunte. Recuperado de: https://www.sebrae.com.br/sites/PortalSebrae/ideias/como-montar-uma-fabrica-de-argamassae-rejunte,62497a51b9105410VgnVCM1000003b74010aRCRD

Serviço Brasileiro de Apoio às Micro e Pequenas Empresas - SEBRAE. (2020). Panorama do setor da construção civil. Recuperado de: https://atendimento.sebraesc.com.br/inteligencia/infografico/panorama-do-setor-de-construcao-civil 
Serviço Brasileiro de Apoio às Micro e Pequenas Empresas - SEBRAE. (2019). Panorama da Construção Civil. Recuperado de: https://atendimento.sebraesc.com.br/inteligencia/infografico/panorama-do-setor-de-construcao-civil

Zdanowicz, J. E. (2002). Fluxo de caixa: uma decisão de planejamento e controle financeiros. 9 ed. Porto Alegre: Sagra Luzzato. 